\title{
Iron Shortage and Bile Salts Play a Major Role in the Expression of ompK Gene in Vibrio anguillarum
}

\author{
MOHAMMED A. HAMOD ${ }^{1,2 *}$, PATIT P. BHOWMICK ${ }^{1}$, YASSAMIN N. SHUKUR ${ }^{2}$, IDDYA KARUNASAGAR ${ }^{1}$ \\ and INDRANI KARUNASAGAR ${ }^{1}$
}

\author{
${ }^{1}$ Department of Fishery Microbiology, Karnataka Veterinary, Animal and Fisheries Sciences University, \\ College of Fisheries, Mangalore - 575 002, India. \\ ${ }^{2}$ Department of Biotechnology, College of Sciences, University of Baghdad, Baghdad - 10070, Iraq
}

Submitted 6 October 2013, revised 30 December 2013, accepted 1 February 2014

Abstract

The outer membrane protein K, OmpK first identified in Vibrio parahaemolyticus has been shown to be a receptor for a broad host range vibriophage KVP40 infecting members of the Vibrionaceae. In the study, the effect of culture conditions on the expression of ompK in V. anguillarum was studied using real-time PCR. The expression increased significantly in the presence of bile salts and iron chelating agent 2, 2' bipyridine, suggesting a role for this protein in bile resistance and also in iron acquisition by V. anguillarum. OmpK induction by iron limitation and the presence of bile salts was reconfirmed by western blot technique after growing the cells in trypticase soy broth supplemented with bile salts, blood and 2, 2' bipyridine. We surmise that the expression of OmpK protein of V. anguillarum is bile salt and iron chelating agent-dependent.

Ke y w o r d s: Vibrio anguillarum, OmpK expresion, Real-time PCR, Western blot, bile salt, iron deprivation

\section{Introduction}

Vibrio anguillarum, a marine bacterium belonging to the family Vibrionaceae is a major bacterial pathogen of marine and estuarine fish throughout the world (Myhr et al., 1991). V. anguillarum infection results in fatal haemorrhagic septicaemia in marine fish when the immune system of fish is compromised or when the mucosal surfaces are damaged (Croxatto et al., 2007).

The outer membrane of Gram-negative bacteria consists of phospholipids and proteins. The proteins make up to $50 \%$ of the outer membrane mass. In recent years, these outer membrane proteins have attracted attention, since they have an important role in the hostbacteria interaction in adherence, uptake of nutrients including iron from the host, and subverting host defense mechanisms (Li et al., 2008).

To date, studies on V. anguillarum outer membrane proteins have focused on OmpU, the major outer membrane protein present in large quantities and $\mathrm{OM} 2$, the induced outer membrane protein, which is known to be linked with virulence of the organism (Pedersen et al., 1997; Simón et al., 1996; Wang et al., 2003). However, more interest has been given to the role of membrane proteins involved in iron uptake such as FetA and FvtA.
Recently it was demonstrated that the expression of these proteins decreases spectacularly with iron readiness (Naka and Crosa, 2012). Some Omps play a role in efflux of salinity, therefore their expression increases with the rise of salt concentration (Davey et al., 1998, Kao et al., 2009).

Although the presence of OmpK has been demonstrated in V.cholerae, V.parahaemolyticus, V.harveyi and V.alginolyticus (Inoue et al., 1995a), only the protective efficacy of $V$.alginolyticus $\mathrm{OmpK}$ against fish vibriosis caused by $V$. alginolyticus has been reported (Qian et al., 2008). Therefore in this study, we attempted to look for OmpK at DNA and protein level; in addition, we also studied the expression of $\operatorname{smpK}$ gene by real-time PCR and the effect of different culture conditions on the expression to get an insight on the role of this outer membrane protein in V. anguillarum.

\section{Experimental}

\section{Materials and Methods}

Bacterial strain and growth condition. V.anguillarum NB10 kindly provided by Dr. Sahul Hameed (Abdul Hakeem College, India) was maintained at

* Corresponding author: M.A. Hamod, Department of Biotechnology, College of Sciences, University of Baghdad, Baghdad - 10070, Iraq; phone: +964 7715130069; fax: +91 824 2246384, e-mail: m_a_hamod@yahoo.com 
$-80^{\circ} \mathrm{C}$ in nutrient broth containing $30 \%$ glycerol (Sanyo Corporation, Japan). The culture was set up by inoculating $5 \mathrm{ml}$ of sterile trypticase soya broth (TSB) supplemented with $1 \% \mathrm{NaCl}$ and incubated overnight at $28^{\circ} \mathrm{C}$.

Nucleic acid extractions. DNA extraction was carried out from $1 \mathrm{ml}$ of $V$. anguillarum culture using the method described by Ausubel et al., 1995. The DNA pellet was resuspended in Tris-EDTA buffer $(10 \mathrm{mM}$ Tris-Cl, 1 mM EDTA, pH 8). RNA extraction and purification was done by RNeasy Protect Bacteria Mini Kit (Qiagen, USA) according to the protocol described by the manufacturer. Extracts were subsequently treated with DNase I (Fermentas International Inc., Canada), according to manufacturer's guidelines to remove any remaining DNA.

Primer design. To study the ompK gene of V.anguillarum, the primers F-k502: GGCTTCCAAATTTCAACCAA and R-k699: TTTAAGGCCGTAGCCAACAG were designed using the Primer3 software ((http:// biotools.umassmed.edu/bioapps/primer3 www.cgi), based on the ompK gene (GenBank accession no. FJ705222.1). The primers F-rpoA: CGTAGCTGAAGGCAAAGATGA and R-rpoA: AGCTGGAACATAACCACGA previously reported by Defoirdt et al., 2007 were used to amplify rpoA, which served as an internal standard gene.

Effect of growth conditions. The experiment was carried out in $100 \mathrm{ml}$ TSB inoculated with $1 \mathrm{ml}$ overnight culture followed by incubation at $28^{\circ} \mathrm{C}$. To study the effect of $\mathrm{NaCl}$ on $V$. anguillarum growth, bacteria were grown in TSB supplemented with the following $\mathrm{NaCl}$ concentrations; $1 \%$ (control), 2\%, 3\% and 4\%. To study the effect of bile salts, the culture was grown in media containing $0.1 \%, 0.2 \%$, and $0.4 \%$ bile salts, and also grown in media free of bile salt (control). The effect of blood was determined by using $1 \%$, and $2 \%$ of fresh blood; culture grown in media without blood were taken as control. The effect of the iron chelating agent 2, 2'-bipyridine was studied by growing the bacteria with or without $20 \mathrm{mM} \mathrm{2,2'-bipyridine.} \mathrm{The} \mathrm{effect} \mathrm{of}$ a combination of $1 \%$ blood and $100 \mathrm{mM}$ of 2, 2'-bipyridine was also studied.

cDNA synthesis. Reverse transcription was carried out according to the protocol of Fermentas Life Sciences (Fermentas International Inc., Canada). Briefly, the RNA was reverse transcribed to cDNA from $2 \mu \mathrm{g}$ of RNA using $2 \mu \mathrm{l}$ of reverse primer $(100 \mathrm{ng} / \mu \mathrm{l})$ and $0.5 \mu \mathrm{l}$ of RevertAid $\mathrm{H}$ minus (Fermentas International Inc., Canada) at $42^{\circ} \mathrm{C}$ for $1 \mathrm{~h}$. OmpK cDNA was tested by PCR using primers F-k502, and R-k699 and cDNA of the internal standard gene ( $r p o A$ subunit) was tested by PCR using primers F-rpo $A$ and R-rpoA. cDNA samples were stored at $-20^{\circ} \mathrm{C}$ for further use.

Real-time PCR analysis. Quantification of expression level of the $o m p K$ gene was done by real-time PCR using 7300 Real-time PCR System (Applied Biosystems, Foster city, USA). Validation of the real-time PCR was done by amplifying serial dilutions of cDNA synthesized from $1 \mu \mathrm{g}$ of RNA isolated from bacterial samples (Livak and Schmittgen, 2001). to carry out relative quantification using the $2^{-\Delta \Delta c t}$ formula.

The appropriate primer concentrations $(200 \mathrm{nM}$ for $o m p K$ and $300 \mathrm{nM}$ for $r p o A$ ) were used for thermal cycling which included an initial activation at $50^{\circ} \mathrm{C}$ for $2 \mathrm{~min}$, initial denaturation at $95^{\circ} \mathrm{C}$ for $10 \mathrm{~min}$ followed by 45 cycles of denaturation at $95^{\circ} \mathrm{C}$ for $15 \mathrm{~s}$, primer annealing at $60^{\circ} \mathrm{C}$ for $45 \mathrm{~s}$ and elongation at $72^{\circ} \mathrm{C}$ for $30 \mathrm{~s}$ and a melting-curve program $\left(95^{\circ} \mathrm{C}\right.$ for $15 \mathrm{~s}$ and $60^{\circ} \mathrm{C}$ for $30 \mathrm{~s}$ ). This was performed for each gene to check for amplification of the targeted fragments. Each reaction was performed in triplicate and the average value was considered for data analysis and statistical validation. Amplification data was recorded at the end of each elongation step.

Analysis of relative gene expression was performed using the $2^{-\Delta \Delta c t}$ method of Livak and Schmittgen (2001). The expression of the target genes was normalized to the endogenous control by calculating $\Delta \mathrm{C}_{\mathrm{T}}$ and expressed relative to a calibrator by calculating $\Delta \Delta \mathrm{C}_{\mathrm{T}}$ $\left(\Delta \Delta \mathrm{C}_{\mathrm{T}}=\Delta \mathrm{C}_{\mathrm{T} \text { target }}-\Delta \mathrm{C}_{\mathrm{T} \text { calibrator }}\right)$. The control values (5 h time interval, $0.5 \% \mathrm{NaCl}, 0 \%$ bile salt, iron and 2, 2'-bipyridine) of each experimental condition were used as calibrator. The expression level of the $\operatorname{ompK}$ gene in each condition of the study was tested by an independent sample student $\mathrm{t}$-test for calculating $\Delta \mathrm{Ct}$ data. Significance level was taken at 5\%.

Western blotting. Bacteria grown under different culture conditions that resulted in a significant difference in the production of $o m p K$ gene were harvested by centrifugation at $4000 \mathrm{~g}$ for $10 \mathrm{~min}$ and were lysed by discontinuous sonication on ice at $20-30 \mathrm{~W}$ with six $10 \mathrm{~s}$ bursts followed by centrifugation at $5000 \mathrm{~g}$ for $20 \mathrm{~min}$ to remove the unlysed cells. Cell lysates were resolved in 15\% SDS-PAGE (without staining) and electrotransferred onto nitrocellulose blotting membrane (Pall, New York, USA) at a constant voltage of $50 \mathrm{~V}$ for $1 \mathrm{~h}$ according to our previous article (Hamod et al., 2012). The membrane was blocked with $3 \%$ bovine serum albumin (BSA) overnight at $4^{\circ} \mathrm{C}$. This was followed by three times washes with phosphate buffer saline containing 0.05\% Tween-20 (PBST) followed by 3 washes with phosphate buffer saline (PBS) (1 min each time). The protein bands on the membrane were allowed to react with the rabbit anti-OmpK serum developed by us as described in our previous work (Hamod et al., 2012) diluted 1:100 with gentle agitation at room temperature for $1 \mathrm{~h}$, followed by washing and further incubation with horse radish peroxidase (HRP)-conjugated goat anti-rabbit immunoglobulin G antibodies (Sigma, Missouri, USA) diluted 1:1000 for 
(a)

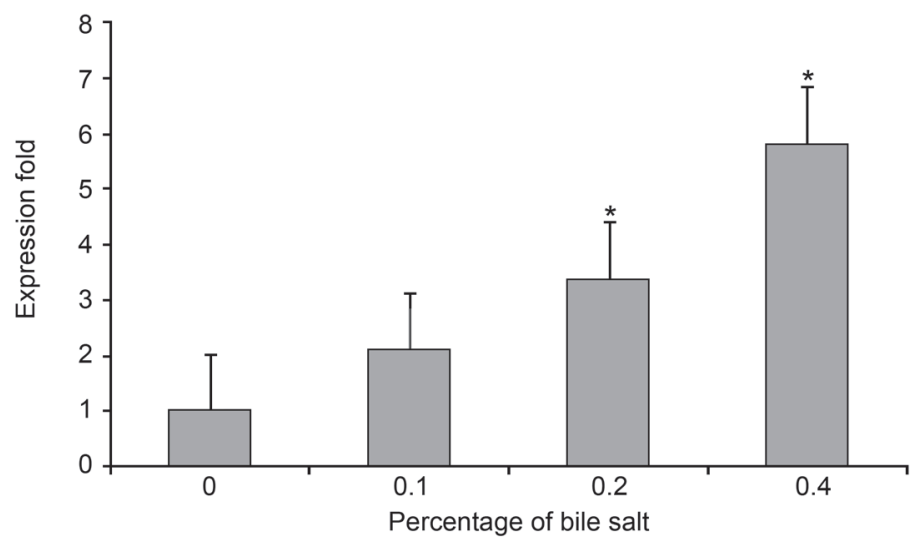

(b)

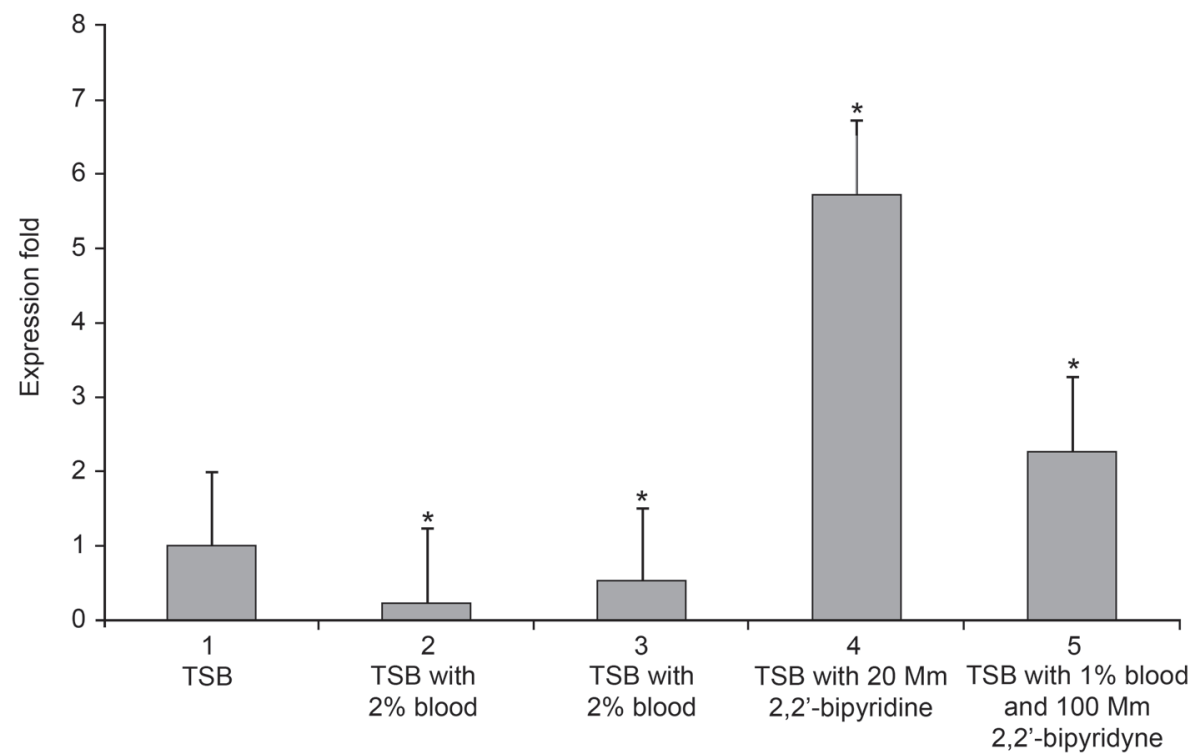

Fig 1. Expression of V. anguillarum ompK gene (a) in the presence of different concentrations of bile salts (b) in the presence

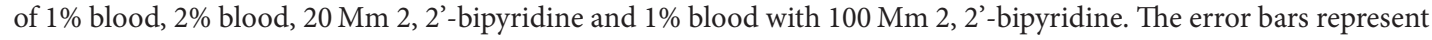
the standard deviation of three independent measurements of $\Delta \Delta \mathrm{CT}$ based on bacterial mRNAs. Data that are significantly different $(P<0.01)$ from the calibrator are marked with an asterisk.

$1 \mathrm{~h}$. The reaction was carried out by dipping the membrane in tetramethylbenzidine solution (Merck, India) after thorough washing with PBS, stopped by rinsing with distilled water and visualized.

\section{Results}

Effect of culture conditions on the expression of ompK gene. Study on the effect of varying salt concentrations on growth and OmpK expression of $V$. anguillarum $\mathrm{NB} 10$ showed that $\mathrm{NaCl}$ concentrations up to $3 \%$ had a minimal effect. Expression of ompK at 2\% $\mathrm{NaCl}$ (2.74 fold) was observed to be higher than at $1 \%, 3 \%$ and $4 \%$ of $\mathrm{NaCl}$. The growth of $\mathrm{V}$. anguillarum NB10 seemed to decrease with increasing bile salt concentration in the medium while the expression of ompK increased with increase in bile salt concentration (Fig. 1a). Expression of $\operatorname{ompK}$ gene was the highest at $0.4 \%$ bile salt concentration ( 5.8 fold) (Fig. 1a). Supplementation of iron chelating agent 2, 2'-bipyridine increased $o m p K 5.7$ fold (Fig. 1b). On supplementation of culture medium with fresh human blood, the expression of ompK decreased (Fig. 1b). When both $20 \mathrm{mM}$ 2, 2'-bipyridine and blood were supplemented, ompK expression was reduced to 2.3 fold compared to 5.7 fold in the presence of 2, 2'-bipyridine alone (Fig. 1b).

Western blot analysis. Positive bands with molecular weight of $28 \mathrm{KDa}$ were seen only in the lanes containing cell lysates of $V$. anguillarum grown with $0.4 \%$ of bile salts, $20 \mathrm{mM}$ bipyridine, and 1\% of blood with $100 \mathrm{mM}$ bipyridine (Fig. 2). No bands appeared in the other lanes containing the cell lysates of $V$. anguillarum grown with $4 \% \mathrm{NaCl}, 2 \%$ blood supplement or bacteria grown in TSB without any supplementation.

\section{Discussion}

$V$. anguillarum is a causative agent of vibriosis in finfish and invertebrates such as bivalves and crustaceans. Vibriosis results in massive losses to the aquaculture 


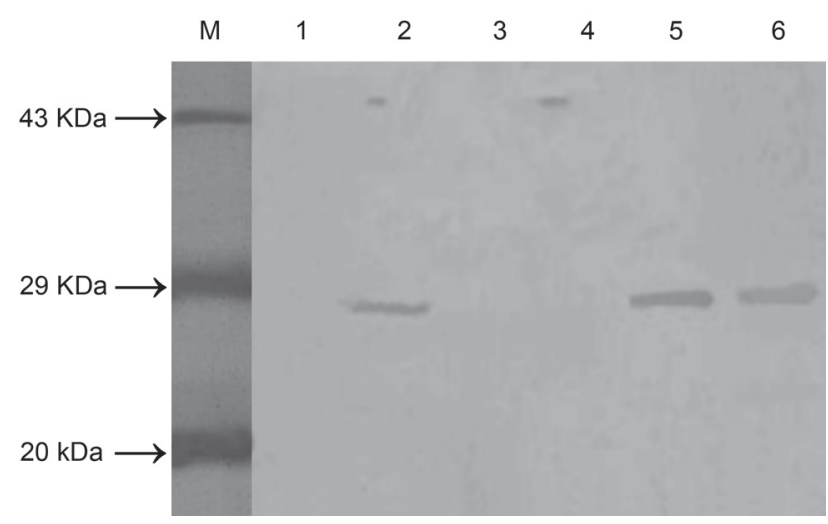

Fig. 2. Western blot for V. anguillarum OmpK grown inpresence of bile salts, $\mathrm{NaCl}$, bipyridine and blood. Protein marker (M), TSB (1), $0.4 \%$ bile salt (2), $4 \% \mathrm{NaCl}$ (3), $2 \%$ of blood (4), $20 \mathrm{mM}$ bipyridine (5), $1 \%$ of blood and $100 \mathrm{mM}$ bipyridine(6).

industry (Garcia et al., 1997). V.anguillarum NB10 initially isolated by Norqvist et al., 1989 was the representative isolate chosen for this study, since it belongs to serotype O1, which is globally accepted as a highly pathogenic serotype. Since serotype O1 assumes variable outer membrane profile under different conditions (Simón et al., 1996), the use of a strain of this serotype would be appropriate for the study of any novel outer membrane protein.

Gram-negative bacteria such as V. anguillarum are surrounded by a bilayer outer membrane in which proteins are interspersed. Porins in bacterial outer membranes have a regulatory role in nutrient uptake, facilitating the transport of specific nutrient molecules (Achouak et al., 2001; Nikaido, 1994). Few outer membrane proteins such as OmpA and general porins are constitutively expressed in high levels in the cell whereas the majority of outer membrane proteins are induced with increased synthesis occurring only under certain circumstances (Koebnik et al., 2000). A $26 \mathrm{kDa}$ outer membrane protein, OmpK common to Vibrio species was first reported by Inoue et al. (1995a; 1995b) and shown to serve as a receptor for a broad-host-range vibriophage, KVP40. Although the genes encoding OmpK in V. cholerae, V. harveyi and V. alginolyticus are similar (Inoue et al., 1995a), variations for this gene in terms of the number of amino acids they encode have been reported for V.alginolyticus and V.harveyi (Li et al., 2008; Qian et al., 2008). So far, there has been no report on the structure and functions of ompK gene in V. anguillarum.

Polyclonal antibody was raised against the purified recombinant OmpK protein in rabbit in our work (Hamod et al., 2012). Surprisingly a positive band was detected only in the case of purified OmpK protein. The protein in the cell lysate of V.anguillarum was undetected by Western blot. It has been reported that expression of OMP is related to environmental condi- tions like temperature, salinity, availability of nutrients and oxygen (Nandi et al., 2005).

Real-time PCR technique, a reliable quantitative method for measuring gene expression (Nielsen and Boye, 2005) was used in this study to determine the effect of varying environmental factors such as salt concentration, bile salt concentration and iron chelating agent on the expression of ompK gene in V.anguillarum.

V. anguillarum, a marine bacterium, well recognized as a pathogen of marine and estuarine fish, encounters different osmotic environments. The outer membrane proteins have a crucial role in maintaining the osmotic state of the organism during any salt stress. In this study growing V.anguillarum at salt concentrations higher than $2 \%$, which is the optimum for its growth, did not upregulate ompK expression suggesting that ompK probably is not involved in osmoregulation. On the contrary, using the proteomic approach of Kao et al., 2009 showed that both ompU and ompW are highly expressed at $3.5 \% \mathrm{NaCl}$ and are possibly involved in osmoregulatory function in V. anguillarum.

$V$. anguillarum being a fish pathogen, when ingested by fish is likely to be exposed to bile in the fish gut and therefore might be in possession of mechanisms for survival in the gut environment. Our study shows that expression of $o m p K$ is upregulated in the presence of bile salts. Though growth seemed to be suppressed at $0.4 \%$ bile salt (data not shown), expression of $o m p K$ was 5 fold higher (Fig. 1a) suggesting a role for this protein in bile resistance. Wang et al., 2003 showed OmpU to play a role in bile resistance in V.anguillarum. In Escherichia coli two outer membrane proteins OmpF and OmpC confer bile salt resistance. While OmpF is sensitive to bile salt concentration changes at low temperature and salinity, $\mathrm{OmpC}$ responds to alteration in bile salt concentration at elevated temperature (Nikaido and Rosenberg, 1983). Similarly, we suggest that in V.anguillarum, in addition to OmpU (Wang et al, 2003), OmpK may also be playing an important role in bile salt resistance and its uptake.

Iron uptake mechanisms are involved in conferring virulence to V.anguillarum. Two iron uptake mechanisms have been reported in this organism viz production of anguibactin and vanchrobactin (Lemos et al., 1988). We observed that expression of ompK was induced in the presence of iron chelating agent 2,2'-bipyridine and this is partially offset if blood is present in the medium (Fig. 1b), which probably suggests that OmpK in $V$. anguillarum responds to changes in iron level in the environment.

Therefore, V. anguillarum strain was grown in TSB medium supplemented with $20 \mathrm{~m} \mathrm{~mol}^{-1} 2$,2'-bipyridine, $0.4 \%$ bile salt, $4 \% \mathrm{NaCl}, 2 \%$ of blood and combination of biypiridine and blood for the detection of OmpK protein by Western blot. A band with $28 \mathrm{kDa}$ (Fig. 2) was 
visualized in the case of V. anguillarum strain grown in bile salt, bipyridine and combination of blood and bipyridine. This result further confirms the role of OmpK protein in bile salt resistant and iron uptake.

\section{Acknowledgment}

The first author gratefully acknowledges the research fellowship awarded by DBT-TWAS Ph.D programme and also thankfully acknowledges the support of the University of Baghdad.

\section{Literatures}

Achouak W., T. Heulin and J.M. Pagés. 2001. Multiple facets of bacterial porins. FEMS Microbiol Lett. 199: 1-7.

Ausubel F.M., R. Brent, R.E. Kingston, D.D. Moore, J.G. Seidman, J.A. Smith and K. Struhl. 1995. Short Protocols in Molecular Biology: A compendium of methods from Current Protocol in Molecular Biology. New York John Wiley and Sons.

Croxatto A., J. Lauritz, C. Chen and D. Milton. 2007. Vibrio anguillarum colonization of rainbow trout integument requires a DNA locus involved in exopolysaccharide transport and biosynthesis. Environ. Microbiol. 9: 370-382.

Davey M.L., R.E.W. Hancock, L.M. Mutharia. 1998. Influence of culture conditions on expression of the 40-kilodalton porin protein of Vibrio anguillarum serotype O2. Appl Environ Microbiol. 64: 138-146.

Defoirdt T., C.M. Miyamoto, T.K. Wood, E.A. Meighen, P. Sorgeloos, W. Verstraete and P. Bossier. 2007. The natural furanone (5Z)-4-bromo-5-(bromomethylene)-3-butyl-2(5H)-furanone disrupts quorum sensing-regulated gene expression in Vibrio harveyi by decreasing the DNA-binding activity of the transcriptional regulator protein LuxR. Environ. Microbiol. 9: 2486-2495.

Garcia T., K. Otto, S. Kjelleberg and R. Nelson. 1997. Growth of Vibrio anguillarum in Salmon intestinal mucus. App. Environ. Microbiol. 63: 1034-1039.

Hamod M.A., M.S. Nithin, Y.N. Shukur, I. Karunasagar and I. Karunasagar. 2012. Outer membrane protein $\mathrm{K}$ as a subunit vaccine against $V$. anguillarum. Aquaculture. 354-355: 107-110.

Inoue T., S. Matsuzaki and S. Tanaka. 1995a. A $26 \mathrm{kDa}$ outer membrane protein, OmpK, common to Vibrio species is the receptor for a broad-host-range vibriophage. KVP40. FEMS Microbiol. Lett. 125: 101-106.

Inoue T., S. Matsuzaki and S. Tanaka. 1995b. Cloning and sequence analysis of Vibrio parahaemolyticus ompK gene coding a $26-\mathrm{kDa}$ outer membrane protein, OmpK, that serves as receptor for a broad-host-range vibriophage, KVP40. FEMS Microbiol. Lett. 134: 245-249.

Kao D.Y., Y.C. Cheng, T.Y. Kuo, S.B. Lin, C.C. Lin, L.P. Chow and W.J. Chen. 2009. Salt-responsive outer membrane proteins of Vibrio anguillarum serotype $\mathrm{O} 1$ as revealed by comparative proteome analysis. J. Appl. Microbiol. 106: 2079-2085.
Koebnik R., Locher K.P and P. Van Gelde. 2000. Structure and function of bacterial outer membrane proteins: barrels in a nut shell. Mol. Microbiol. 37: 239-253.

Lemos M.L., P. Salinas, A.E. Toranzo, J.L. Braja and J.H. Crosa. 1988. Chromosome-mediated iron uptake system in pathogenic strain of V. anguillarum. J. Bacteriol. 170: 1920-1925.

Li N., Bai J., S. Wu, X. Fu, H. Lao, Y. Xing and C. Shi. 2008. An outer membrane protein, $\mathrm{OmpK}$, is an effective vaccine candidate for Vibrio harveyi in Orange-spotted grouper (Epinephelus coioides). Fish Shellfish Immun. 25: 829-833.

Livak K.J. and T.D. 2001. Schmittgen. Analysis of relative gene expression data using real-time quantitative PCR and the $2^{-\triangle \Delta C T}$ method. Methods. 25: 402-408.

Miller E.S., J.F. Heidelberg, J.A. Eisen, W.C. Nelson, A.S. Durkin, A. Ciecko, T.V. Feldblyum, O. White, I.T. Paulsen, W.C. Nierman, J. Lee, B. Szczypinski and C.M. Fraser. 2003. Complete genome sequence of the broad-host-range vibriophage KVP40: comparative genomics of a T4-related bacteriophage. J. Bacteriol. 185: 5220-5233. Myhr E.L., J.L. Larsen, A. Lillehaug, R. Gudding, M. Heum and T. Hástein. 1991. Characterization of Vibrio anguillarum and closely related species isolated from farmed fish in Norway. Appl. Environ. Microbiol. 57: 2750-2757.

Nandi B., R.K. Nandy, A. Sarkar and A.C. Ghose. 2005. Structural features, properties and regulation of the outermembrane protein $\mathrm{W}$ (OmpW) of Vibrio cholerae. Microbiology 151: 2975-2986.

Naka H. and J.H. Crosa. 2012. Identification and characterization of a novel outer membrane protein receptor FetA for ferric enterobactin transport in Vibrio anguillarum 775 (pJM1). Biometals. 25: 125-133.

Nielsen K. and M. Boye. 2005. Real-time quantitative reverse transcription-PCR analysis of expression stability of Actinobacillus pleuropneumoniae housekeeping genes during in vitro growth under iron-depleted conditions. Appl Environ Microbiol. 71: 2949-2954.

Nikaido H. and E.Y. Rosenberg. 1983. Porin channels in Escherichia coli: studies with liposomes reconstituted from purified proteins. J. Bacteriol. 153: 241-252.

Nikaido H. 1994. Porins and specific diffusion channels in bacterial outer membranes. J. Biol. Chem. 296: 3905-3908.

Norqvist A., W.A. Hagstr and H. Wolf-Watz. 1989. Protection of rainbow trout against vibriosis and furunculosis by the use of attenuated strains of Vibrio anguillarum. Appl. Environ. Microbiol. 55: 1400-1405.

Pedersen K., L. Gram, D.A. Austin and Austin B. 1997. Pathogenicity of Vibrio anguillarum serogroup $\mathrm{O} 1$ strains compared to plasmids, outer membrane protein profiles and siderophore production. J. Appl. Microbiol. 82: 365-371.

Qian R., Z. Xiao, C. Zhang, W. Chu, L. Wang, H. Zhou, Y. Wei and L. Yu. 2008. A conserved outer membrane protein as an effective vaccine candidate from Vibrio alginolyticus. Aquaculture. 278: 5-9. Simón M., A. Mathes, A. Blanch and H. Engelhardt. 1996. Characterization of a porin from the outer membrane of Vibrio anguillarum. J. Bacteriol. 178: 4182-4188.

Wang S., J. Lauritz, J. Jass and D. Milton. 2003. Role for the major outer-membrane protein from Vibrio anguillarum in bile resistance and biofilm formation. Microbiology 149: 1061-1071. 
